\title{
RADIAL ARTERY HARVESTING FOR CORONARY BYPASS OPERATIONS: NEUROLOGIC COMPLICATIONS AND THEIR POTENTIAL MECHANISMS
}

Timothy A. Denton, MDa

Luca Trento ${ }^{\mathrm{a}}$

Myles Cohen, $\mathrm{MD}^{\mathrm{b}}$

Robert M. Kass ${ }^{\mathrm{a}}$

Carlos Blanche, $\mathrm{MD}^{\mathrm{a}}$

Sharo Raissi, $\mathrm{MD}^{\mathrm{a}}$

Wen Cheng, MD

Gregory P. Fontana, MD

Alfredo Trento, MD
Objectives: We sought to determine the incidence of self-reported neurologic hand complications after radial artery harvest for coronary artery bypass grafting.

Methods: Between February 20, 1996, and December 31, 1999, 615 patients underwent coronary bypass operations with radial arteries. A scripted telephone interview was performed, collecting data on perceived thumb weakness and sensation abnormalities in the distribution of the radial nerve in 560 patients. The average time to follow-up interview was $14.5 \pm 9$ months.

Results: Neurologic complications were reported in $30.1 \%$, decreased thumb strength in $5.5 \%$, and any sensation abnormality in $18.1 \%$ of patients. There was a high rate of symptom improvement over an average of $8.7 \pm 7.5$ months, such that only $12.1 \%$ of patients reported symptoms without any improvement. Associations between thumb weakness and sensory abnormalities imply median nerve damage in some patients. There were statistically significant associations between neurologic complications and diabetes, peripheral vascular disease, elevated creatinine levels, smoking, and number and site of radial artery harvest.

Conclusions: The overall rate of self-reported neurologic complications after radial artery harvest was higher than previously reported. These symptoms may be attributable to radial and median nerve injury caused by trauma and devascularization. These data have important implications not only in attempting to improve harvesting techniques but also in guiding informed consent before coronary artery bypass grafting. (J Thorac Cardiovasc Surg 2001;121:951-6)
$T^{\mathrm{h}}$ e radial artery (RA) has become more popular as a bypass graft because the issues of spasm have been aggressively addressed by the use of various vasodilating regimens. ${ }^{1-3}$ The intermediate and late-term patency rates vary from $83.0 \%$ to $96.8 \%,{ }^{4-9}$ which may justify its continued use. Few complications from the harvest of RAs have been reported. Most patients do not have any evidence of hand ischemia during routine daily activities, and few have demonstrable ischemia on hand exercise. ${ }^{10,11}$ The RA harvest site may even have fewer infectious complications than saphenous vein sites. ${ }^{12}$

From the Divisions of Cardiothoracic Surgery, Cardiology, ${ }^{\mathrm{a}}$ and Orthopedic Surgery, ${ }^{\mathrm{b}}$ Cedars-Sinai Medical Center, Los Angeles, Calif.

Copyright (C) 2001 by The American Association for Thoracic Surgery

$0022-5223 / 2001 \$ 35.00+0 \quad \mathbf{1 2} / \mathbf{1} / \mathbf{1 1 2 8 3 3}$

doi:10.1067/mtc.2001.112833
Neurologic complications of RA harvest have been attributed to direct radial nerve damage and have been reported as rare. ${ }^{13-16}$ On the basis of anecdotal cases of dysesthesia and hand weakness after RA harvest seen in our division over the last few years, we sought to measure the self-reported rate of sensory and motor deficits related to RA harvest and determine potential mechanisms.

\section{Methods}

Surgical technique. All RAs are obtained by specially trained physician assistants who routinely perform both saphenous vein and RA harvesting. All patients undergo preoperative Allen testing ${ }^{17}$ with Doppler ultrasonography to assure adequate flow through the RA and the brachial and ulnar arteries. Adequate digital artery flow is determined by using alternate compression of both the RAs and ulnar arteries.

RA harvest is initiated by identifying the border of the brachioradialis muscle, and a skin incision is made starting $3 \mathrm{~cm}$ from the anterior elbow crease to $3 \mathrm{~cm}$ from the wrist crease. An arm tourniquet is not used. Blunt dissection exposes the RA, and electrocautery is used to control bleeding. Venous 
Table I. Demographic and clinical characteristics of patients with and without harvested RAs over the study period

\begin{tabular}{lccc}
\hline Characteristic & $R A$ & No RA & P value \\
\hline $\mathrm{n}$ & 640 & 1829 & - \\
Age (y) & $64.0 \pm 10$ & $71.6 \pm 10$ & $<.001$ \\
Sex (\% male) & 85.8 & 68.1 & $<.001$ \\
Prior surgery (\%) & 17.0 & 12.5 & .004 \\
Smoking (\%) & 56.0 & 49.0 & .002 \\
Diabetes (\%) & 29.1 & 30.7 & $\mathrm{NS}$ \\
Hypertension (\%) & 59.0 & 60.8 & $\mathrm{NS}$ \\
Hypercholesterolemia (\%) & 66.0 & 48.1 & $<.001$ \\
PVD (\%) & 16.9 & 23.2 & $<.001$ \\
Angina (\%) & 84.0 & 76.0 & $<.001$ \\
Congestive heart failure (\%) & 12.4 & 25.5 & $<.001$ \\
Creatinine (mg/dL) & $1.1 \pm 0.5$ & $1.3 \pm 1.3$ & $<.001$ \\
Ejection fraction (\%) & 53.5 & 51.3 & $<.001$ \\
Total diseased vessels & $2.5 \pm 0.7$ & $2.3 \pm 0.8$ & $<.001$ \\
Total distal anastomoses & $3.3 \pm 0.9$ & $2.8 \pm 1.0$ & $<.001$ \\
Concomitant valve operation (\%) & 24.3 & $<.001$ \\
Left internal thoracic artery (\%) & 9.1 & 88.1 & .009 \\
Right internal thoracic artery (\%) & 92.0 & 10.6 & $<.001$ \\
Surgical mortality & 31.7 & 5.4 & $<.003$ \\
Radial grafts & 2.9 & - & -
\end{tabular}

Data are presented as means \pm SD and proportions $(\%)$.

NS, Not significant.

branches of the adjacent veins are divided and clipped. Branches of the RA are clipped on the proximal side and uniformly controlled distally with electrocautery. When visible, the superficial radial and antebrachial-cutaneous nerves are avoided completely. The artery is clamped proximally and distally, and the interposing segment is taken as a pedicle. The remaining ends are closed by using a suture-ligature with or without clipping. Before closure, hemostasis is assured with electrocautery, subcutaneous fat is approximated with running 3-0 Monocryl sutures (Ethicon, Inc, Somerville, NJ), and the skin is closed with running 4-0 Monocryl sutures.

Data collection. From our prospective cardiothoracic surgery database, ${ }^{18}$ we retrieved a list of patients who underwent RA harvest for coronary artery bypass grafting between February 20, 1996, and December 31, 1999. All patients were contacted by telephone, and a formal scripted interview was performed to elicit symptoms attributable to nerve damage. Patients were asked (1) if there were any problems with the hand from which the RA was harvested, (2) if there were problems with thumb strength on the side from which the RA was harvested, (3) if there were sensation abnormalities on the back of the hand on the side in which the RA was harvested, (4) if there were sensation abnormalities on the palm side of the hand on the side in which the RA was harvested, (5) if they had these symptoms immediately after the operation and, if yes, (6) when the symptoms resolved. Patients were allowed to make general comments on their outcomes, and any complaints regarding the hand were investigated further. Any symptoms reported above the wrist were not analyzed in this study. Patient demographics, clinical history, and intraoperative data were obtained from our prospective database.
Data analysis. The dichotomous variables obtained from the interview were entered into a database containing demographic and clinical variables. Statistically significant differences between groups were measured by use of the $\chi^{2}$ test in the case of categoric variables and the Student $t$ test for continuous variables. Analysis of variance was used for determining statistically significant differences between multiple groups. Predictor variables included the preoperative and operative variables listed in Table I.

\section{Results}

Our initial experience with RAs started in the first quarter of 1996, and their rate of use has increased every quarter until a plateau rate of $52.2 \%$ in the last quarter of 1999. There were 640 patients who had the RA harvested between the trial dates. We excluded 20 patients who had died and 5 patients who had strokes about whom data could not be reliably obtained. Demographic and clinical characteristics of the patients are presented in Table I. The mean time between the operation and telephone follow-up was $14.5 \pm 9.0$ months (range, 4.1-45 months).

Patient characteristics. Table I shows the demographic and clinical characteristics of patients with and without RA harvesting over the same time period. Patients in whom the RA was used were younger, more often men, had more prior operations, and had more hypercholesterolemia. Smoking was more common in the RA group, although they had less peripheral vascular disease (PVD), more angina, less congestive heart failure, a lower creati- 
nine level, and a higher ejection fraction. Anatomically, the RA group had more diseased vessels and therefore more distal anastomoses. The RA group also had a higher rate of use of the internal thoracic artery and fewer valve operations. The surgical mortality was lower in the RA group. The left RA was used in $86.4 \%$, the right RA in $9.2 \%$, and both RAs in $4.3 \%$ of patients.

Follow-up data. Follow-up data were available on $560(91 \%)$ of the eligible 615 patients. Table II shows the rates of self-reported neurologic hand complications after RA harvesting. Any neurologic complication was reported in $30.1 \%$ of patients, with decreased thumb strength occurring in $5.5 \%$ of patients. Any sensation abnormality occurred in $18.1 \%$, dorsal sensation abnormalities occurred in $13.8 \%$, and palmar abnormalities were seen in $12.7 \%$ of patients. Some patients described a series of atypical symptoms (other abnormality), such as intermittent sharp pain, generalized hand weakness, and other types of numbness $6.3 \%$ of the time. Although our use of the RA has increased to $52.2 \%$ in the fourth quarter of 1999 , the overall rate of neurologic complications has remained constant when analyzed by means of analysis of variance $(P=.2)$.

Symptom improvement. Of the 169 patients with any history of symptoms, 101 reported that their symptoms improved over time, indicating that $12.1 \%$ had long-term residua. The time to symptom improvement averaged $8.7 \pm 7.5$ months.

Symptom associations. The superficial branch of the radial nerve is sensory for the dorsum of the hand and a small portion of the lateral thenar eminence. The proximal interosseus branch of the radial nerve is the motor for the thumb and finger extensors. Thus, it remained unclear why palmar sensory abnormalities and thumb weakness were reported because these abnormalities would be associated with median nerve damage. We therefore probed the data, seeking specific associations between motor and sensory abnormalities by dividing the sensory abnormalities into 3 groups: dorsal abnormality only, palmar abnormality only, and simultaneous dorsal and palmar abnormalities. We then compared those 3 groups with patients who did and did not have thumb weakness (Table III). If a patient had thumb weakness, there was a $16 \%$ chance of palmar sensation abnormalities. In the absence of thumb weakness, there was a $3.8 \%$ chance of palmar sensation abnormalities $(P=.003)$. Again, with thumb weakness, there was a $35 \%$ chance of both palmar and dorsal sensation abnormalities and a $6.6 \%$ chance of both palmar and dorsal sensation abnormalities in the absence of thumb weakness $(P<.001)$. There was no statistical association between dorsal sensation abnormalities only and thumb weakness.
Table II. Incidence of self-reported neurologic problems

\begin{tabular}{lrc}
\hline Symptom & $n /$ total & Proportion \\
\hline Any abnormality & $169 / 560$ & $30.1 \%$ \\
Thumb strength & $31 / 559$ & $5.5 \%$ \\
Sensation abnormality & $101 / 559$ & $18.1 \%$ \\
$\quad$ Dorsum & $77 / 559$ & $13.8 \%$ \\
Palm & $71 / 559$ & $12.7 \%$ \\
Other abnormality & $43 / 558$ & $6.3 \%$ \\
Long-term residua & $68 / 560$ & $12.1 \%$ \\
\hline
\end{tabular}

Predictors of neurologic complications. We performed univariate analyses to determine associations between each outcome variable (symptom) and each predictor variable (Table IV). Bilateral RA harvest and smoking were predictors of any abnormality. Diabetes, PVD, serum creatinine levels, and congestive heart failure were associated with decreased thumb strength. Smoking was associated with any sensation abnormality, and dorsal sensation abnormalities were associated with smoking and harvesting of the right RA. There were no statistically significant predictors of palmar abnormalities or other abnormalities.

\section{Discussion}

RAs are being used at ever increasing rates ${ }^{14}$ because of their perceived benefits. In this study we have demonstrated that patients report a significant number of hand symptoms after harvesting of the RA for coronary artery bypass grafting, higher than previously reported in the literature. ${ }^{13-16}$ Fortunately, the neurologic symptoms seem to improve over time, such that only $12.1 \%$ of patients had permanent deficits, a figure similar to those found in other reports in the medical literature. In addition, the symptoms and their specific associations indicate that there is not only radial nerve damage but also that the median nerve can also be damaged in the harvesting process. Finally, these data would support mechanisms of injury beyond that of direct physical trauma.

Patterns of injury. We found that patients have a variety of neurologic hand abnormalities after RA harvest. The presence of dorsal sensation abnormalities suggests damage to the superficial radial nerve, a logical assumption because of its close association with the RA. Patients also complain of atypical symptoms analogous to causalgia, which is often attributed to radial nerve damage. But patients also report having both palmar sensation abnormalities and thumb weakness, abnormalities most often associated with the median nerve. Complaints of thumb weakness are most often 
Table III. Associations between sensory and motor abnormalities

\begin{tabular}{lccc}
\hline Sensory abnormality location & Thumb weakness & No thumb weakness & P value \\
\hline Palmar only & $16.1 \%(5 / 31)$ & $3.8 \%(20 / 528)$ & .003 \\
Dorsal only & $6.5 \%(2 / 31)$ & $5.6 \%(29 / 528)$ & .97 \\
Both palmar and dorsal & $35.5 \%(11 / 31)$ & $6.6 \%(35 / 528)$ & $<.001$ \\
\hline
\end{tabular}

Table IV. Univariate predictors of self-reported hand complications

\begin{tabular}{lll}
\hline Symptom & \multicolumn{1}{c}{ Predictors } & P value \\
\hline Any abnormality & Bilateral RA harvest & .03 \\
& Smoking & .04 \\
Thumb strength & Diabetes & .006 \\
& PVD & .04 \\
& Creatinine level & .006 \\
& Congestive heart failure & .04 \\
Any sensation abnormality & Smoking & .03 \\
Dorsal abnormality & Smoking & .01 \\
& Right RA harvest & .03 \\
Palmar abnormality & None & - \\
Other abnormality & None & - \\
\hline
\end{tabular}

attributed to weakness of the flexor pollicus longus, a muscle innervated by the anterior interosseus nerve, a branch of the median nerve. This muscle, along with the distal branches of the anterior interosseus nerve, may also receive blood supply from the RA.

Furthermore, our data correlating the types of symptoms would support a mechanism involving the median nerve. There was no correlation between thumb weakness and dorsal sensation abnormalities, but there was a strong correlation between thumb weakness and palmar abnormalities.

Mechanisms of injury. Symptoms of radial nerve injury would be easy to attribute to direct trauma during RA harvest. Although the median nerve is within 1 to $2 \mathrm{~cm}$ of the RA at the wrist, there is no direct and only minimally indirect manipulation that could cause significant damage, although we cannot exclude a local carpal tunnel hematoma or edema. A hint at a potential mechanism is revealed in the univariate clinical associations between symptoms and individual patient characteristics. Note in Table IV that many of the clinical variables associated with specific neurologic symptoms are clinical conditions that are related to vascular disease: PVD, diabetes, smoking, and elevated creatinine levels. Thus, on the basis of our preliminary data, we hypothesize that vascular insufficiency should be considered as a possible mechanism for these neurologic abnormalities.
In the forearm the median nerve has at least 3 patterns of blood supply. ${ }^{19-21}$ The most common pattern $(70 \%)$ is when the nerve receives collaterals from both the RA and ulnar artery in the distal forearm. If branches of the RA that supply the median nerve are interrupted, then the nerve may become devascularized, and an ischemic neuropathy would develop if there is inadequate flow from the ulnar collaterals (eg, presence of vascular disease). Median nerve ischemia has been well described. ${ }^{22}$

Recovery of function. The majority of patients with symptoms recover some or all of their neurologic function over a period of approximately 8 months. This period of time corresponds to recovery of nerve function after devascularization or local trauma.

Minimizing trauma. The approach to reduction in these complications is multifaceted. First, because much of the damage is to the superficial radial nerve and because it courses near the RA, its direct manipulation must be avoided, and its indirect manipulation (by retraction) must be minimized. Second, care must be taken when collecting the distal portion of the RA because clipping vessels medially may compromise median nerve blood supply. We are presently undertaking a study to determine the location and distribution of visible distal radial branches. In support of this approach, there are data to indicate that the proximal segment of the RA is a superior conduit. ${ }^{23}$ Newer techniques, such as the Harmonic Scalpel (Ethicon EndoSurgery, Inc, Somerville, NJ), may be available to decrease the morbidity of RA harvest. ${ }^{24}$ The exact role of endoscopic harvesting of the RA has not yet been determined. $^{25}$

Preoperative assessment. Most of the preoperative assessment of the RA has focused on its role as a conduit. Many centers perform some type of Allen test, ${ }^{17,26}$ analogous to the method described here, whereas others have developed simpler methods. ${ }^{27}$ In addition to measures of blood flow, on the basis of our data, patients should also receive informed consent regarding potential neurologic hand complications that could include dysesthesia and thumb weakness in as many as $30 \%$ of patients. The majority of these symptoms will show some type of improvement, leaving a population 
of $12 \%$ with residual symptoms. Furthermore, patients with diabetes, PVD, and elevated creatinine levels should also be alerted to their higher risk of thumb strength abnormalities.

Patient selection. Although we use the RA in over $50 \%$ of our patients, it is considered a second-line conduit after internal thoracic arteries. Thus we most often use it in young patients who might benefit from total arterial revascularization or in patients in whom adequate saphenous veins are not available. We avoid its use in larger coronary arteries, where competitive flow might induce vasospasm or occlusion.

Limitations. The major limitation of this study is that it measured self-reported neurologic symptoms and not objective testing. Although objective testing can provide accurate information on a patient's ability to acquire and process sensory data, it cannot provide accurate information on whether the patient actually perceives sensory abnormalities. In the hand there is a significant amount of overlap in the sensory areas, such that a branch from another nerve may be able to provide sensory information. Although a damaged nerve may not acquire accurate sensory information, it can provide aberrant stimuli that result in patient symptoms analogous to the "phantom limb" syndrome. Furthermore, patient perceptions of outcome are important, and we must address any concerns that the patients may have regarding bothersome complications.

In summary, we have demonstrated, in a series of 560 patients, that the overall neurologic complication rate from the harvesting of RAs was $30.1 \%$, with sensory loss in $18.1 \%$ and loss of thumb strength in $5.5 \%$. These complications are related to both superficial radial nerve and median nerve damage. Potential mechanisms for damage include direct and indirect trauma and may be exacerbated by devascularization injury. These data are important in guiding informed consent regarding potential neurologic symptoms after RA harvest and in developing optimal surgical techniques to minimize these complications.

Received for publication July 20, 2000; revisions requested Sept 21, 2000; revisions received Oct 3, 2000; accepted for publication Nov 8, 2000.

Address for reprints: Timothy A. Denton, MD, Room 6215, Cedars-Sinai Medical Center, 8700 Beverly Blvd, Los Angeles, CA 90048 (E-mail: denton@cshs.org).

\section{REFERENCES}

1. Chester AH, Amrani M, Borland JAA. Vascular biology of the radial artery. Curr Opin Cardiol 1998;13:447-52.

2. Buxton B, Fuller J, Gaer J, Liu J, Mee J, Sinclair R, et al. The radial artery as a bypass graft. Curr Opin Cardiol 1996;11:591-8.
3. Cable DG, Caccitolo JA, Pearson PJ, O'Brien T, Mullany CJ, Daly RC, et al. New approaches to prevention and treatment of radial artery graft vasospasm. Circulation 1998;98(Suppl):II-1521.

4. Chen AH, Nakao T, Brodman RF, Greenberg M, Charney R, Menegus M, et al. Early postoperative angiographic assessment of radial artery grafts used for coronary artery bypass grafting. $\mathrm{J}$ Thorac Cardiovasc Surg 1996;111:1208-12.

5. Possati G, Gaudino M, Alessandrini F, Luciani N, Glieca F, Trani C, et al. Midterm clinical and angiographic results of radial artery grafts used for myocardial revascularization. J Thorac Cardiovasc Surg 1998;116:1015-21.

6. Acar C, Ramsheyi A, Pagny JY, Jebara V, Barrier P, Fabiani JN, et al. The radial artery for coronary artery bypass grafting: clinical and angiographic results at five years. J Thorac Cardiovasc Surg 1998;116:981-9.

7. Bhan A, Gupta V, Choudhary SK, Sharma R, Singh B, Arrarwal $\mathrm{R}$, et al. Radial artery in CABG: could the early results be comparable to internal mammary artery graft? Ann Thorac Surg 1999;67:1631-6.

8. Tatoulis J, Buxton BF, Fuller JA. Bilateral radial artery grafts in coronary reconstruction: technique and early results in 261 patients. Ann Thorac Surg 1998;66:714-9.

9. Buxton BF, Fuller JA, Tatoulis J. Evolution of complete arterial grafting for coronary artery disease. Texas Heart Inst J 1998;25:17-23.

10. Dumanian GA, Segalman K, Mispireta LA, Walsh JA, Hendrickson MF, Wilgis EF. Radial artery use in bypass grafting does not change digital blood flow or hand function. Ann Thorac Surg 1998;65:1284-7.

11. Serricchio M, Gaudino M, Tondi P, Gasbarrini A, Gerardino L, Santoliquido A, et al. Hemodynamic and functional consequences of radial artery removal for coronary artery bypass grafting. Am J Cardiol 1999;84:1353-6.

12. Trick WE, Scheckler WE, Tokars JI, Jones KC, Smith EM, Reppen ML, et al. Risk factors for radial artery harvest site infection following coronary artery bypass graft surgery. Clin Infect Dis 2000;30:270-5.

13. Brodman RF, Frame R, Camacho M, Chen A, Hollinger I. Routine use of unilateral and bilateral radial arteries for coronary artery bypass graft surgery. J Am Coll Cardiol 1996;28:959-63.

14. Royse AG, Royse CF, Shah P, Pallav S, Williams A, Kaushik S, et al. Radial artery harvest technique, use and functional outcome. Eur J Cardiothorac Surg 1999;15:186-93.

15. Shapira OM, Alkon JD, Aldea GS, Madera F, Lazar HL, Shemin RJ. Clinical outcomes in patients undergoing coronary artery bypass grafting with preferred use of the radial artery. J Card Surg 1997;12:381-8.

16. Sudhakar CB, Forman DL, Dewar ML, Shaw RK, Fusi S. Free radial artery grafts: surgical technique and results. Ann Plast Surg 1998;40:408-11

17. Cable DG, Mullany CJ, Schaff HV. The Allen test. Ann Thorac Surg 1999;67:876-7.

18. Denton TA, Chaux A, Matloff JM. A cardiothoracic surgery information system for the next century: implications for managed care. Ann Thorac Surg 1995;59:486-93.

19. Pecket P, Gloobe H, Nathan H. Variations in the arteries of the median nerve. Clin Orthop Related Res 1973;97:144-7.

20. Gajisin S, Zbrodowski A. Local vascular contribution of the superficial palmar arch. Acta Anatomica 1993;147:248-51.

21. Zbrodowski A, Buchs JB. Blood supply of the median nerve in the carpal tunnel. Hand 1983;15:310-6. 
22. Sugimoto H, Miyaji N, Ohsawa T. Carpal tunnel syndrome: evaluation of median nerve circulation with dynamic contrastenhanced MR imaging. Radiology 1994;190:459-66.

23. Chester AH, Marchbank AJ, Borland JAA, Yacoub MH, Taggart DP. Comparison of the morphologic and vascular reactivity of the proximal and distal radial artery. Ann Thorac Surg 1998;66:1972-7.

24. Psacioglu H, Atay Y, Cetindag B, Saribulbul O, Buket S, Hamulu A. Easy harvesting of radial artery with ultrasonically activated scalpel. Ann Thorac Surg 1998;65:984-5.
25. Terada Y, Uchida A, Fukuda I, Hochberg J, Mitsui T, Sato F. Endoscopic harvesting of the radial artery as a coronary artery bypass graft. Ann Thorac Surg 1998;66:2123-4.

26. Pola P, Serricchio M, Flore R, Manasse E, Favuzzi A, Possati GF. Safe removal of the radial artery for myocardial revascularization: a Doppler study to prevent ischemic complications to the hand. J Thorac Cardiovasc Surg 1996;112:737-44.

27. Johnson WH, Cromartie RS, Arrants JE, Wuamett JD, Holt JM. Simplified method for candidate selection for radial artery harvesting. Ann Thorac Surg 1998;65:1167.

\section{Online-www.aats.org}

Now you can get The Journal of Thoracic and Cardiovascular Surgery online.

The Journal online brings you faster delivery time, easy searching of current and back issues, links to PubMed, AATS, WTSA, and other important sites, and more. Visit the Journal online today.

\section{Receive tables of contents by e-mail}

To receive the tables of contents by e-mail, sign up through our Web site at http://www.mosby.com/jtcvs

Choose E-mail Notification

Simply type your e-mail address in the box and click the Subscribe button. Alternatively, you may send an e-mail message to majordomo@mosby.com. Leave the subject line blank and type the following as the body of your message: subscribe jtcvs_toc

You will receive an e-mail to confirm that you have been added to the mailing list. Note that TOC e-mails will be sent out when a new issue is posted to the Web site. 